\title{
Nanocurcumin Modulates miR-223-3p and NF- $\kappa B$ Levels in the Pancreas of Rat Model of Polycystic Ovary Syndrome to Attenuate Autophagy Flare, Insulin Resistance and Improve B Cell Mass
}

\author{
Nermeen Z Abuelezz $\mathbb{D}^{\prime}$ \\ Marwa E Shabana $\mathbb{D}^{2}$ \\ Laila Rashed (D) $^{3}$ \\ George NB Morcos 3,4 \\ 'Biochemistry Department, College of \\ Pharmaceutical Sciences and Drug \\ Manufacturing, Misr University for \\ Science and Technology, Giza, Egypt; \\ 2Pathology Department, Medical \\ Division, National Research Center, \\ Cairo, Egypt; ${ }^{3}$ Medical Biochemistry and \\ Molecular Biology Department, Faculty of \\ Medicine, Cairo University, Cairo, Egypt; \\ ${ }^{4}$ Basic Medical Science Department, \\ Faculty of Medicine, King Salman \\ International University, El Tur, Egypt
}

Purpose: Polycystic ovary syndrome (PCOS) is a prevalent female endocrine disorder. 50$70 \%$ of PCOS patients suffer from glucose intolerance, insulin and $\beta$ cell impairments. Updated studies reveal the crucial regulatory role of inflammation modulators in various diseases, by manipulating autophagy and oxidative stress. However, the data available about autophagy in PCOS pancreas, especially in relation to inflammation key players are little. This study investigated pancreatic autophagy status in PCOS rat model, with miR-223-3p and NF- $\mathrm{KB}$ levels as pivotal regulators of oxidative stress-autophagy axis, insulin, and $\beta$ cell integrity. We then analyzed nanocurcumin effects as a putative anti-inflammatory nutraceutical on the disrupted parameters.

Methods: Nanocurcumin was characterized using transmission electron microscopy (TEM) and Fourier-transform IR (FT-IR) spectroscopy. Adult virgin Wistar rats were selected, and PCOS was induced using letrozole $(1 \mathrm{mg} / \mathrm{kg})$. Nanocurcumin was ingested following letrozole. Sex hormones and insulin resistance were determined. miR-223-3p expression was determined using real-time PCR. Immunohistochemistry and Western blotting determined $\beta$ cells, NF-kB, and autophagy markers p62 and LC3II.

Results: PCOS group showed significant disruptions in sex hormones and a double fold increase in glucose and insulin levels, exhibiting insulin resistance. Immunostaining confirmed around $46 \%$ deterioration of $\beta$ cell mass. Real-time PCR showed significant downregulation of miR-223-3p. Immunohistochemistry and Western blotting revealed a drastic upsurge of NF- $\mathrm{kB}$, and autophagy markers p62 and LC3II, confirming bioinformatics target analysis. Interestingly, compared to PCOS group, nanocurcumin $(200 \mathrm{mg} / \mathrm{kg})$ significantly upregulated $\mathrm{miR}-223-3 \mathrm{p}$ expression by $30 \%$. It subsided $\mathrm{NF}-\mathrm{\kappa B}$ and autophagy eruption to restore $\beta$ cell mass and attenuate insulin resistance.

Conclusion: To the best of our knowledge, this study is the first to highlight the vital contribution of miR-223-3p and NF- $\kappa$ B levels in aggravating PCOS pancreatic autophagy and consequent impairments. It spots nanocurcumin potential as an inflammation and autophagy modulator, for possible better management of PCOS complications.

Keywords: autophagy, insulin resistance, cytokines, endocrine system disease

\section{Introduction}

Polycystic ovary syndrome (PCOS) is a widespread female endocrine disorder that affects metabolism, and proliferation in multiple organs. ${ }^{1}$ A status of subclinical chronic inflammation prevails in PCOS, and compared with healthy females, PCOS 


\section{Graphical Abstract}

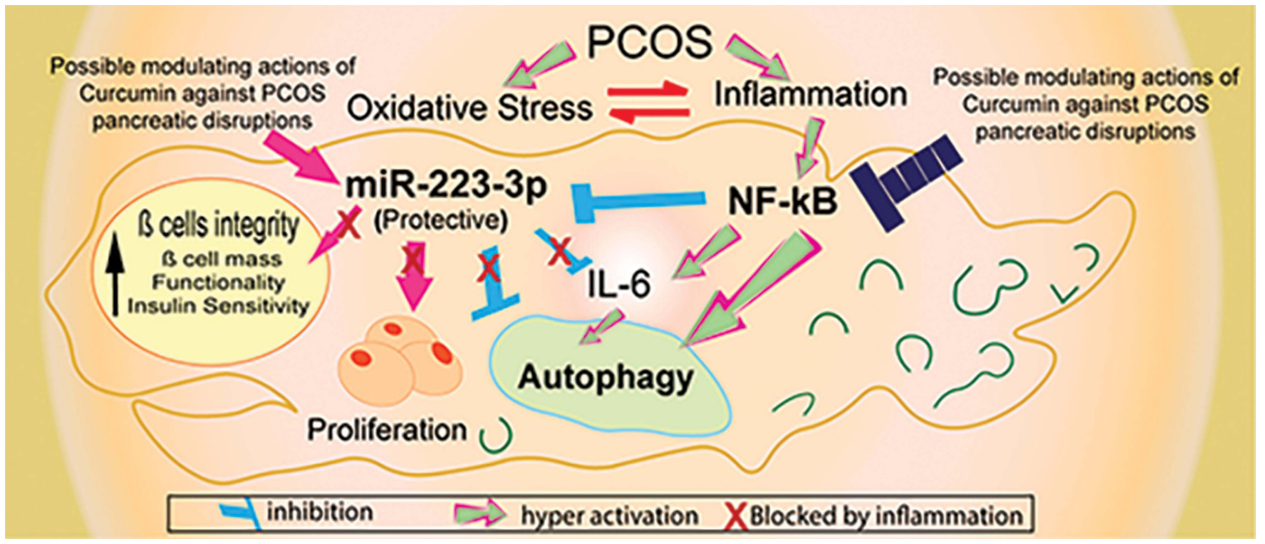

patients are highly liable to develop other serious diseases. $^{2,3}$ Around $50-70 \%$ of PCOS patients suffer from poor glucose tolerance, insulin resistance, decreased $\beta$ cell mass and functionality. ${ }^{4,5}$ Such disruptions are partially attributed to high testosterone levels, but they are continuously reported even independently of obesity or androgen levels. ${ }^{6}$ However, the mechanisms underlying these impairments remain not fully clarified. Inflammation molecules are pivotal players in cellular and molecular homeostasis. ${ }^{7,8}$ Simultaneously, as a protective pathway, balanced autophagy guarantees cellular homeostasis under physiological conditions. ${ }^{9}$ Increased evidence confirms the vital role of the interplay between low-grade inflammation and oxidative stress in PCOS pathogenesis. Where excessive production of reactive oxygen species (ROS) provokes imbalanced second messengers that impact different signaling pathways, varying from sex hormones, to insulin secretion, inflammatory responses, to cell death. ${ }^{10}$ Likewise, increasing evidence now reveals the significant connection between inflammation and autophagy disturbances in multiple metabolic and proliferative disorders, ${ }^{11}$ thus opening the field to improve therapeutic intervention by controlling inflammation and autophagy key players. However, to date, available data on autophagy status in PCOS pancreas, especially concerning the pancreatic pivotal regulators of inflammation and oxidative stress, is little. Recent studies have reported an impaired PI3K/AKT/mTOR pathway in metabolic-related disorders, as this pathway regulates metabolic and proliferative processes across the body. ${ }^{12,13}$ However, the upstream regulators that encounter this pathway to autophagy in PCOS pancreas are still unresolved. The crucial role of inflammatory cytokine nuclear factor $-\kappa \mathrm{B}(\mathrm{NF}-\kappa \mathrm{B})$ in manipulating insulin activity and autophagy during inflammation is constantly emerging. ${ }^{14-16}$ Updated studies reveal the protective role of miR-223-3p, by suppressing $\mathrm{NF}-\kappa \mathrm{B}$ and interfering with autophagy proteins in different disorders. ${ }^{17,18}$ Moreover, because of its role in insulin and inflammatory signaling, miR-223-3p is now suggested as a specific pancreatic biomarker, that assesses prediabetes progression. ${ }^{19}$ However, to the best of our knowledge, no previous study explored miR-223-3p expression level in PCOS pancreas, nor its relation to pancreatic $N F-\kappa B$ and autophagy status, despite the prevalence of insulin and $B$ cell disorders in PCOS.

To this end, naturally derived anti-inflammatory supplements demonstrated cytoprotective benefits in several disorders. $^{20}$ Curcumin is a putative anti-inflammatory and antioxidant nutraceutical; it has proven its effectiveness in inflammatory disorders, neurodegenerative diseases, and diabetes. Recent elegant clinical studies demonstrated the promising activity of curcumin in adjusting androgen and glucose levels in patients with PCOS, through its interaction with inflammatory and oxidative stress pathways and the activation of nuclear factor E2-related factor 2 (Nrf2) function. ${ }^{21}$ Interestingly, curcumin has elicited the ability to modulate autophagy in different cancer types; ${ }^{22}$ however, there is little data concerning its activity on autophagy in PCOS. Furthermore, the poor solubility and rapid metabolism of curcumin in physiological $\mathrm{pH}$ are additional drawbacks against its wider therapeutic use in effective logical doses. These challenges are effectively tackled by formulating curcumin in nano-biocompatible 
forms that remarkably improves curcumin water solubility, and bioavailability. ${ }^{23}$ Therefore, to obtain a deeper understanding of the mechanisms contributing to PCOS pancreas pathology, the present study explored autophagy status in PCOS pancreas, and investigated the expression levels of pancreatic miR-223-3p and NF- $\kappa B$ as pivotal regulators of inflammation, insulin, and autophagy pathways. Finally, we studied the effect of nanocurcumin on the reported disrupted parameters, to test its possible ability to modulate autophagy in PCOS.

\section{Materials and Methods}

\section{Experimental Animals}

Seven-week-old female adult virgin Wistar rats of weight $(180 \pm 20 \mathrm{~g})$ were kept in standard polypropylene cages and fed phytoestrogen-free animal feed and water ad libitum under controlled conditions: (temperature: $23^{\circ} \mathrm{C} \pm$ $2^{\circ} \mathrm{C}$; 12-h dark/light cycle). Rats were acclimatized to laboratory conditions one week before starting the experiment. All cages were kept in the same location and conditions throughout the whole experiment. The study procedures were approved by the ethics committee of College of Pharmaceutical Sciences, MUST University (MUST-BC-2020-03). All animal experiments complied with the ARRIVE guidelines and were conducted following the 1986 UK Animals (Scientific Procedures) Act, and associated guidelines, EU Directive 2010/63/EU for animal experiments.

\section{Material}

Letrozole, clomiphene citrate and curcumin were purchased from Sigma Aldrich (St. Louis, USA). Polyvinyl alcohol (PVA) and carboxymethyl cellulose (CMC) were purchased from Labochem, (EU).

\section{Nanocurcumin Synthesis and Characterization}

Nanocurcumin was used to enhance the solubility of curcumin without compromising its activity. Nanocurcumin was formulated according to the previously mentioned method. ${ }^{12}$ Briefly, curcumin powder was dissolved in chloroform, and the solution was added dropwise to PVA solution with continuous stirring at $70^{\circ} \mathrm{C}$. The temperature was gradually decreased to $40^{\circ} \mathrm{C}$ while stirring until a yellow fluffy mass was formed. The solution was incubated at $-10^{\circ} \mathrm{C}$ overnight, and then centrifuged at $4^{\circ} \mathrm{C}$ to discard the supernatant. Nanocurcumin layer was washed twice, centrifuged, dried, and then lyophilized. Nanocurcumin was characterized using transmission electron microscope (TEM) to detect its size and shape and Fourier-transform IR spectroscope (FT-IR) for chemical characterization. Zeta potential was also determined using Zetasizer Pro (Malvern, UK).

\section{Induction of PCOS}

Letrozole was used for inducing PCOS following the previously established model. ${ }^{24,25}$ All animals except the control group, ingested $1 \mathrm{mg} / \mathrm{kg}$ of letrozole dissolved in $(0.5 \% \mathrm{CMC})$ for 23 consecutive days via oral plastic gavage needles. The control group ingested an equivalent volume of $0.5 \% \mathrm{CMC}$.

\section{Experimental Design}

The sample size was determined using Gpower software program. $^{26}$ Priori power analysis was conducted to test differences between groups, using one-way ANOVA with effect size $(f=0.5)$, and alpha $=0.05$. Fifty-five rats were divided into five equal sized groups $(n=11)$, which were required to achieve a power of 0.82 .

The five groups were classified as follows: Group I: control group, which comprised rats that ingested $0.5 \%$ $\mathrm{CMC}$ solution orally throughout the experiment. Group II: PCOS, which comprised rats that ingested letrozole solution (1 mg/kg) daily. Group III: standard group: which comprised rats that ingested clomiphene citrate $(1 \mathrm{mg} / \mathrm{kg})$ in $0.5 \% \mathrm{CMC}$ orally for 15 days following letrozole ingestion. Group IV (NC-100) and Group V (NC-200): which comprised rats that ingested 100 and $200 \mathrm{mg} / \mathrm{kg}$ of oral nanocurcumin aqueous solution, respectively, for 15 days following letrozole ingestion. Clomiphene and Nanocurcumin were ingested starting from day 24 to 38 (15 days). Clomiphene dose was chosen as established. $^{27,28}$ Nanocurcumin doses (100 and $200 \mathrm{mg}$ / $\mathrm{kg}$ ) were chosen as the best tested doses based on the results of our previous study. ${ }^{12}$ By the end of the experiment, the animals were fasted for $12 \mathrm{~h}$, and then anaesthetized with isoflurane. Blood was collected via lateral retino orbital puncture, and serum was obtained by centrifugation $(2000 \times \mathrm{g}$ for $15 \mathrm{~min})$. The serum samples were stored at $-80^{\circ} \mathrm{C}$ until use. The animals were decapitated, and the ovaries and pancreatic tissues were excised, washed with ice cold saline and used for the corresponding studies. 


\section{miRNA Target Gene Prediction Tools}

Given the relationship between miR-223-3p, NF- $\kappa B$, insulin and autophagy activities, we next examined the potential target genes of miR-223-3p to clarify its putative involvement in the related pathways. TargetScan (http:// www.targetscan.org/vert 72/), ${ }^{29} \mathrm{miRDB}$ (http://www. mirdb.org/) ${ }^{30}$ and microT-CDS (http://diana.imis.athenainnovation.gr/DianaTools/index.php?r=microT_CDS ${ }^{31}$ platforms were used to predict the biological target genes of miR-223-3p. Consensus overlapping genes were extracted via Venn plot analysis. The functional classification of intersecting genes was determined using Panther database (http://pantherdb.org/), ${ }^{32}$ and ToppGene online suites (https://toppgene.cchmc.org/ $)^{33}$ in the following categories: pathways, biological process, molecular function and diseases.

\section{Study Outcomes}

The primary outcomes of this study were as follows: changes in serum sex hormone levels (Testosterone, estradiol and progesterone), changes in serum glucose and insulin levels, an eruption of insulin resistance, changes in pancreatic oxidative stress markers; Malondialdehyde level (MDA), reduced glutathione level (GSH), catalase activity (CAT), changes in pancreatic miR-223-3p expression, changes in pancreatic inflammatory markers interleukin-6 (IL-6) and NF-kB levels, changes in autophagy markers p62 and light-chain 3 type II protein (LC3II) levels. The secondary outcomes included changes in ovarian tissues, changes in $\beta$ cell number and mass and finally changes in islets tissues.

\section{Biochemical Parameters}

Serum was used to detect the levels of sex hormones; (testosterone, estradiol, and progesterone), and metabolic profile; fasting glucose and insulin levels. Pancreatic tissues were collected. A portion was homogenized in ice cold phosphate buffer with protease inhibitor $(10 \% \mathrm{~W} / \mathrm{V}$ homogenate), centrifuged at $10,000 \mathrm{rpm}, 4^{\circ} \mathrm{C}$ for $15 \mathrm{~min}$. The clear supernatant to measure interleukin-6 (IL-6) level and oxidative stress markers: MDA, CAT and GSH.

The protein content in pancreatic tissue homogenate was determined using bicinchoninic acid (BCA) protein assay (Pierce, USA, catalog number: 23225) according to the manufacturer's protocol. Another portion of pancreatic tissue was used for RNA isolation and subsequent quantitative real-time PCR detection of miR-223-3p level. The third portion was used for the Western blotting determination of the specific autophagy marker LC3II, and the final portion was preserved in formalin for histological examination.

\section{Sex Hormone Levels}

The impairment of sex hormones, and most specifically testosterone, the main androgen hormone is the main hallmark of PCOS pathology. In this study, sex hormones (Testosterone, estradiol and progesterone) were determined via spectrophotometric analysis according to the following manufacturers' protocols; ELISA Testosterone (Rat) kit (Biovision, USA, catalog number: K7418; sensitivity: $0.06 \mathrm{ng} / \mathrm{mL}$, intra assay and inter-assay precision CV\% $<12 \%$ ), Rat Estradiol ELISA Kit (My BioSource, USA, catalog number: MBS263466, sensitivity: $5 \mathrm{pg} / \mathrm{mL}$, intra assay $<8 \%$ and inter-assay precision $\mathrm{CV} \%<12 \%$ ), Rat Progesterone ELISA Kit (Cusabio, China, catalog number: CSB-E07282r, sensitivity: $0.2 \mathrm{ng} / \mathrm{mL}$, Intra assay and Inter-assay precision $\mathrm{CV} \%<15 \%$ ).

\section{Metabolic Profile}

Fasting glucose level was determined as previously mentioned ${ }^{34}$ using (Biodiagnostic, Egypt, catalog number: GL 1320). Serum insulin level was quantified by ELISA kit (Cusabio, China, catalog no: CSB-E05070r. Sensitivity: $3.9 \mathrm{nIU} / \mathrm{mL}$, intra-assay precision $<8 \%$ and inter-assay precision $<10 \%$ ) according to the manufacturer's protocol. Finally, HOMA-IR was calculated using HOMA2 calculator program (dtu.ox.ac.uk). HOMA-IR of more than 2 was considered as insulin resistance. ${ }^{35}$

\section{Oxidative Stress}

Pancreatic homogenate was used to determine MDA, CAT enzyme and GSH. ${ }^{36-38}$ Using kits; (Biodiagnostic, Egypt, Catalog numbers: MD 2529, CA 2517, and GR 2511), respectively. The oxidative stress indicators were expressed in terms of their corresponding units/mg protein.

\section{Determination of IL-6 Level}

IL-6 level was determined using ELISA (MyBio Source, Catalog number: MBS2885203) in accordance with the manufacturer's protocol (sensitivity: $7.8 \mathrm{pg} / \mathrm{mL}$. Intraassay precision $<4.3 \%$ and Inter-assay precision $<6.9 \%$ ).

\section{RNA Isolation and Quantitative PCR of miR-223-3p}

Total RNA was isolated using Trizol according to the established protocol. ${ }^{39}$ Briefly, pancreatic tissue was homogenized in $1 \mathrm{~mL}$ of ice cold Trizol reagent in RNAse-free tubes, mixed well by vortexing for 20 seconds and then incubated at room temp for 5 minutes. 
Chloroform $(200 \mu \mathrm{L})$ was then added, and the mixture was shaken for 20 seconds and incubated at room temperature for $5 \mathrm{~min}$., followed by centrifugation $(12,000 \times \mathrm{g}, 15 \mathrm{~min}$ at $\left.4^{\circ} \mathrm{C}\right)$. RNA was precipitated using isopropanol and the samples were centrifuged $\left(12,000 \times \mathrm{g}\right.$ for $10 \mathrm{~min}$ at $\left.4^{\circ} \mathrm{C}\right)$. The RNA pellet was then repeatedly washed with $75 \%$ ethanol, and centrifuged $\left(12,000 \times \mathrm{g}, 5 \mathrm{~min}\right.$ at $\left.4^{\circ} \mathrm{C}\right)$. The supernatant was discarded, and The RNA pellet was dried and eluted using RNAse-free water. RNA purity was determined spectrophotometrically where A260/280 ranged from 1.8 to 2 .

RNA $(1 \mu \mathrm{g})$ was reverse transcribed using QIAGEN miScript II RT Kit with HiSpec buffer (Catalog Number: 218161) by incubation at $37{ }^{\circ} \mathrm{C}$ for $60 \mathrm{~min}$ and then at 95 ${ }^{\circ} \mathrm{C}$ for $5 \mathrm{~min}$. The cDNA product was then used for realtime PCR reactions containing QIAGEN SYBR green Master Mix, universal reverse primer (Catalog number: 218073), and miRNA specific forward primer (Qiagen miScript Primer assay: MS00033320) in accordance with the manufacturer's instructions. RNU6-2 (Qiagen miScript assay: MS00033740) was used as the reaction reference. PCR conditions were as follows: Predenaturation at $95^{\circ} \mathrm{C}$ for $15 \mathrm{~min}, 94^{\circ} \mathrm{C}$ for 15 seconds, and then annealing at $55^{\circ} \mathrm{C}$ for 30 seconds, then extension at $70{ }^{\circ} \mathrm{C}$ for 30 seconds for 40 cycles. The relative quantification of miR223-3p was determined using the $\Delta \Delta \mathrm{Ct}$ formula.

\section{Western Blotting Determination of LC3II}

Western blotting was performed as previously described. ${ }^{40}$ Briefly, pancreatic tissue was added to RIPA lysis buffer and protease inhibitor for tissue homogenization. Cell lysates were collected by centrifugation at $4^{\circ} \mathrm{C}(12,000 \mathrm{rpm}$ for $15 \mathrm{~min})$. Protein level was quantified using BCA assay. Protein samples $(20 \mu \mathrm{g})$ were loaded on SDS-PAG of $10 \%$ and electrophoresis was performed followed by membrane transfer. The membrane was blocked in Tris-buffered saline tween-20 (TBST) with 5\% skimmed milk (for 2 hrs. at room temperature), and then incubated overnight at $4{ }^{\circ} \mathrm{C}$ with rabbit anti-rat primary antibodies diluted with TBST (LC3 II 1:1000, Cell Signaling technology, Catalog number: 3868). The membranes were then washed and incubated with the secondary antibody (Anti-rabbit secondary antibody conjugated to horseradish peroxidase, DAKO, 1:5000) (for $1.5 \mathrm{hr}$. at room temperature). Finally, the blot was washed several times, and the chemiluminescent substrate (ECL) detection system (Cell Signaling, Beverly, MA, USA) was applied for visualization.
Quantification was performed by Image analysis software for assessing band intensity with $\beta$ actin as the control reference.

\section{Histopathology}

The ovary and pancreatic tissues were fixed in $10 \%$ neutral-buffered formalin for at least 72 hours. All specimens were rinsed in water for 30 minutes, followed by ascending grades of alcohol. They were cleared in xylene and embedded in paraffin. Sections of $5 \mu \mathrm{m}$ thickness were cut and stained with hematoxylin and eosin (H\&E) for histopathological investigation. Morphometric analysis was performed using Leica DM-LB microscope and The Leica Qwin 500 Image Analyzer (Cambridge, UK).

\section{Immunohistochemistry} Insulin Immunostaining

Immuno-localization technique for anti-insulin was used as established. ${ }^{41}$ Briefly, the sections were incubated with primary antibodies for rat insulin (polyclonal antibody) (Bio Genex), then biotinylated secondary antibody (Dako-K0690; Dako Universal LSAB Kit) and streptavidin horseradish peroxidase (Dako-K0690). Diaminobenzidine tetrahydrochloride (Sigma-Aldrich, UK) substrate was used for immune-labelling. Finally, the nuclei were stained and mounted in DPX. Ten tissue sections from each slide were used to determine the count of beta cells in islets to assess pancreatic changes.

\section{NF- $\kappa B$, and P62 Immunohistochemical Detection}

Expressions of NF- $\mathrm{kB}$, and P62 were determined by immunohistochemistry as previously established. ${ }^{42}$ Briefly, Blocks were cut into $4 \mu \mathrm{m}$ thickness. All sections were deparaffinized in xylene, placed in graded alcohol concentrations, and then treated for antigen retrieval, and rinsed in distilled water. The specimens were treated with $3 \% \mathrm{H} 2 \mathrm{O} 2$ for 30 minutes. Next, the sections were rinsed and incubated overnight at $4{ }^{\circ} \mathrm{C}$ with the respective primary antibodies (NF-kB: Invitrogen, Catalog number: PA130408, and p62: Abcam, ab91526). After washing, the slides were treated with streptavidin-biotin system (DakoCytomation, Denmark, Catalog number: K0673). Diaminobenzidine tetrahydrochloride chromogen (SigmaAldrich, UK) was then used for visualization. Finally, the results were analyzed using Leica Qwin 500 Image Analyzer (Cambridge, UK). The analyzer automatically calculated the means of area percentage and standard variation. 


\section{Statistical Analysis}

Data were normally distributed and analyzed using Oneway ANOVA test followed by post-hoc. Tukey's test to compare between different means of all groups. Data are represented as mean \pm standard error with $\mathrm{p}<0.05$ considered statistically significant. Statistical analysis was conducted using GraphPad Prism software v.9.0.

\section{Results}

\section{Nanocurcumin Characterization}

Transmission electron microscopy (TEM) using JEOL JEM2200 high resolution, accelerating voltage of $200 \mathrm{kV}$ examination, showed nearly round nanocurcumin particles with an average particle size of $30 \pm 5 \mathrm{~nm}$. The zeta potential of the aqueous solution was $(-20 \mathrm{mV})$, denoting acceptable stability. The FT-IR analysis revealed successfully preserved curcumin characteristic entities, with the peaks denoting aromatic $\mathrm{C}=\mathrm{C}$ stretching at $1602 \mathrm{~cm}^{-1}, \mathrm{C}=\mathrm{O}$ at $1629 \mathrm{~cm}^{-1}$, and peaks at 3410 and $3502 \mathrm{~cm}^{-1}$ denoting $\mathrm{OH}$ of curcumin. Enol C-O and C-O-C peaks at approximately 1317, 1280 and $1202 \mathrm{~cm}^{-1}$. The TEM and FT-IR analysis of the formulated nanocurcumin are shown in Figure 1. Interestingly, the solubility of the formulated nanocurcumin was significantly improved in water as compared with bulk curcumin powder (Supplementary File; Figure 1).

\section{miR-Target Prediction and Functional Analysis of Target Genes}

Potential target genes of miR-223-3p were examined in platforms; TargetScan, miRDB and DIANA using cutoffs; cumulative context ++ score $<0.15$ and target score $>0.51$ to denote high probability and consistency $^{43}$. Venn plot diagram identified 40 consensus genes that are highly regulated by miR-223-3p and are previously validated, including: ATG7, Ataxin, FOXO1, FOXO3 which are both autophagy and insulin-regulating genes; and inflammation genes: IL-6, interleukin-6 signal transducer (IL6ST), NF-IB and NF-IA that upregulate NF-kB.

Meanwhile, the functional classification of gene ontology was conducted using Panther and Toppgene databases in categories: Pathways, Biological Process, Molecular Function and diseases. The main target pathways included: cellular response to oxidative stress, Phosphatidylinositol 3-kinase (PI3K)/AKT signaling, interleukin signaling pathway, insulin signaling pathway and autophagic cell death. Interestingly, the top disease related to the consensus genes was polycystic ovary syndrome. Detailed consensus genes and genes functional classification results are provided in the (Supplementary File; Table S1 $-\underline{S 3}$ and Figures 2 and $\underline{3}$ ).

\section{Serum Sex Hormones Profile}

ANOVA test showed a significant difference between means; (Testosterone: $\mathrm{F} 4,50=48.19, \mathrm{p}<0.05$, Estradiol: $\mathrm{F} 4,50=92.14, \mathrm{p}<0.05$ and Progesterone: $\mathrm{F} 4,50=87.22, \mathrm{p}<0.05)$. Testosterone level was significantly increased in PCOS group, whereas estradiol and progesterone levels were significantly decreased compared with control group. Additionally, while the clomiphene treated group showed significant restoration of sex hormone levels, nanocurcumin treatment alleviated the hormonal disruptions in a dose-dependent manner as shown in Figure 2.
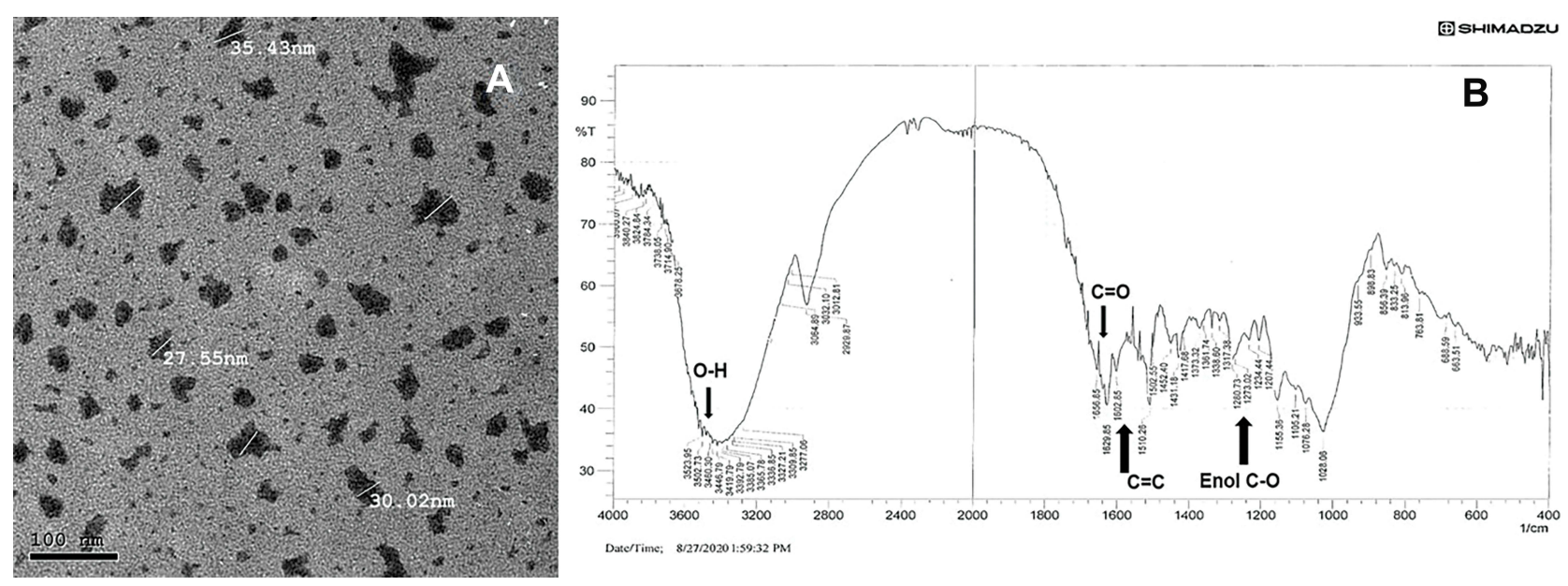

Figure I Photomicrograph of the formulated nanocurcumin using (A) TEM and (B) FT-IR analysis of the formulated nanocurcumin. 
A

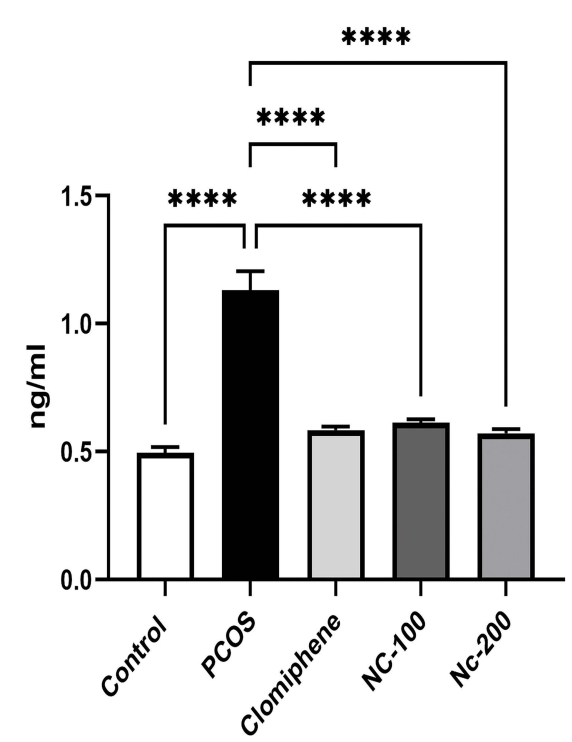

B

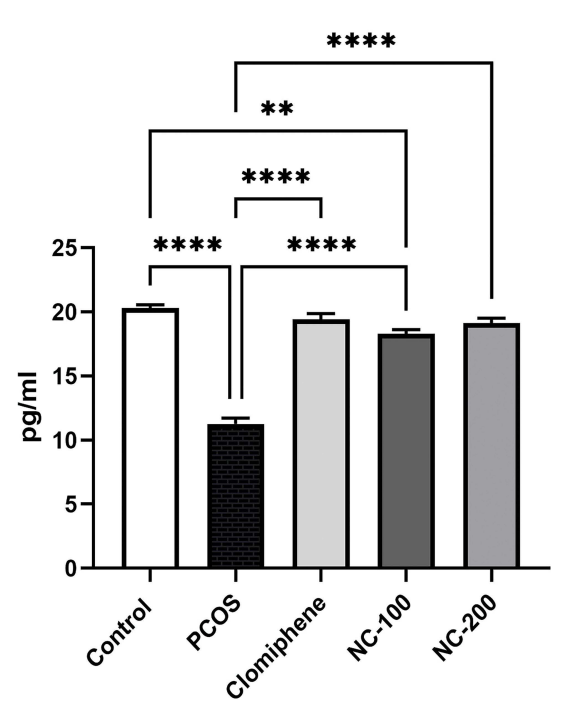

C

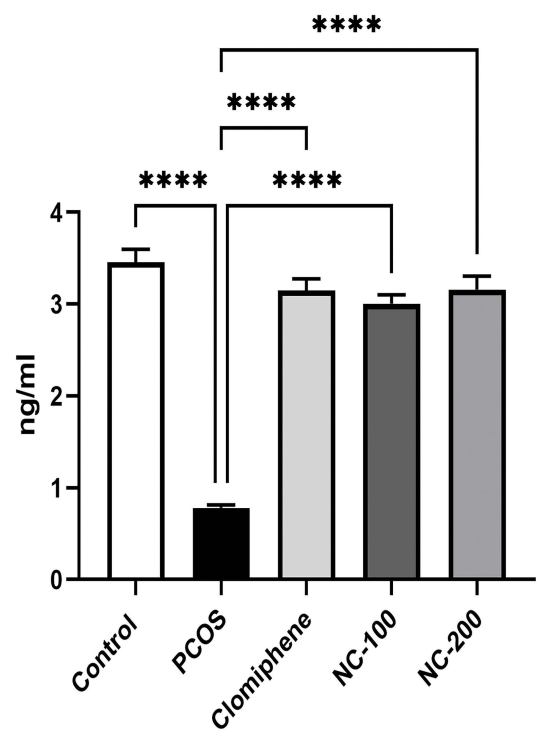

Figure 2 Serum sex hormonal profile of different groups showing $(\mathbf{A})$ Testosterone, $(\mathbf{B})$ Estradiol, $(\mathbf{C})$ Progesterone levels. $* *$ Denotes $\mathrm{p}$ value $<0.0 \mathrm{I}, * * * *$ Denotes $\mathrm{p}$ value $<$ 0.0001 .

\section{Metabolic Profile}

Significant differences in glucose level $(\mathrm{F} 4,50=211.5, \mathrm{p}<$ $0.05)$, insulin levels $(\mathrm{F} 4,50=66.96, \mathrm{p}<0.05)$ and insulin resistance $(\mathrm{F} 4,50=85.13, \mathrm{p}<0.05)$ were recorded. The PCOS group exhibited hyperglycemia and hyperinsulinemia, resulting in significant insulin resistance. Interestingly, nanocurcumin treatment significantly decreased blood glucose and insulin levels with the higher dose of nanocurcumin retaining HOMA-IR to 1.1 (Figure 3 and Table 1).

\section{Oxidative Stress Markers}

The oxidative stress markers significantly differed: MDA: F4, $50=242.7, \mathrm{p}<0.05$, GSH: F4, $50=69.19, \mathrm{p}<0.05$ and Catalase enzyme: F4, $50=78.14, \mathrm{p}<0.05$. The PCOS
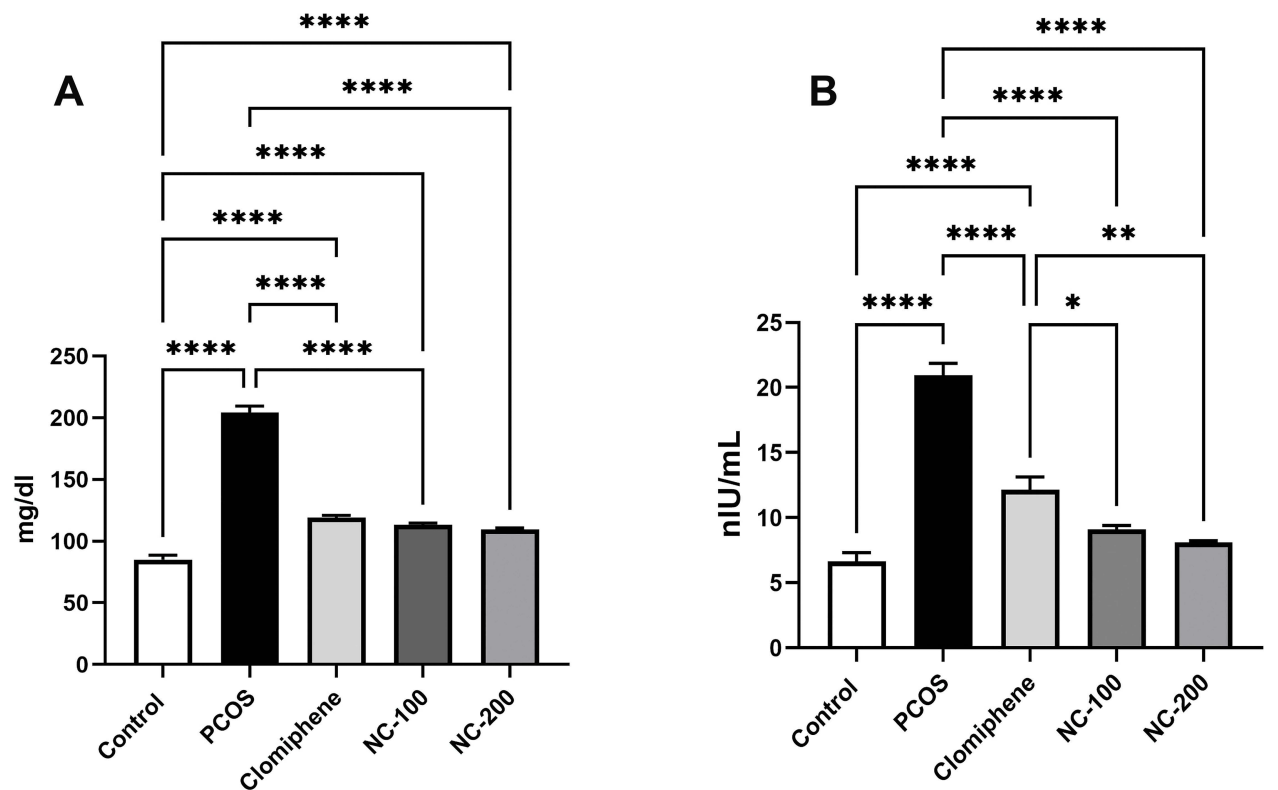

Figure 3 Metabolic profile showing $(\mathbf{A})$ serum glucose level and $(\mathbf{B})$ serum insulin level in the different groups. $*$ Denotes $\mathrm{P}$ value $<0.05$, $*$ Denotes $\mathrm{P}$ value $<0.01$, $* * * *$ Denotes $\mathrm{p}$ value $<0.0001$. 
Table I Insulin Resistance (HOMA- IR)

\begin{tabular}{|l|c|}
\hline Groups & HOMA-IR \\
\hline Control & $0.85 \pm 0.09$ \\
\hline PCOS & $3.2 \pm 0.16^{\mathrm{a}, \mathrm{c}}$ \\
\hline Clomiphene & $1.66 \pm 0.14^{\mathrm{a}, \mathrm{b}}$ \\
\hline NC-100 & $1.27 \pm 0.034^{\mathrm{a}, \mathrm{b}}$ \\
\hline NC-200 & $1.1 \pm 0.1^{\mathrm{b}, \mathrm{c}}$ \\
\hline
\end{tabular}

Notes: Insulin resistance of different groups as represented by HOMA-IR; ${ }^{a}$ Denotes significance versus control, benotes significance against PCOS. ${ }^{\mathrm{C} D e n o t e s ~ s i g n i f i c a n c e ~ v e r s u s ~ c l o m i p h e n e . ~}$

group manifested a dramatic increase in MDA level and a significant decrease in GSH and CAT enzyme compared with control. Both nanocurcumin doses significantly restored MDA, GSH levels and catalase enzyme back around normal levels more significantly than did clomiphene (Figure 4).

\section{Interleukin-6 (IL-6 Pancreatic Tissue Level)}

With ANOVA analysis $(\mathrm{F} 4,50=512.6, \mathrm{p}<0.05)$, PCOS group showed about four times elevation in IL-6 level. Both the smaller dose of nanocurcumin and clomiphene lowered IL-6, whereas the larger dose of nanocurcumin managed to restore IL-6 level back to approach normal ranges (Figure 5).

\section{miR- 223-3p Expression Level}

The expression level of miR-223-3p differed among groups $(\mathrm{F} 4,50=102.14, \mathrm{p}<0.05)$. The PCOS group manifested significant downregulation of miR-223-3p by around $30 \%$ in comparison with control group. Treatment with either clomiphene or nanocurcumin significantly modulated miR223-3p level in pancreatic tissues (Figure 6).

\section{Western Blotting Analysis of LC3 II}

LC3II expression is a distinguished marker used to assess autophagy activity. The Western blot analysis of the tested samples revealed significant differences in LC3II expression among different groups $(\mathrm{F} 4,50=149, \mathrm{p}<0.05)$. The PCOS group showed a remarkable eruption of autophagy activity as compared with the control group. Treatment with the smaller dose of nanocurcumin relatively decreased this disruption. Meanwhile, both clomiphene and the larger dose of nanocurcumin effectively elicited a significant $60.5 \%$ and $60 \%$ decrease in LC3II level, respectively $(\mathrm{p}<0.05)$, to reinstate autophagy activity closest to the normal control group (Figure 7).

\section{Histopathological Examination Ovary Tissue Examination}

The control group showed healthy ovarian tissue with normal oocytes lining of granulose cells. PCOS group successfully manifested numerous follicular cysts, thin or absent granulosa cells and the absence of oocytes.
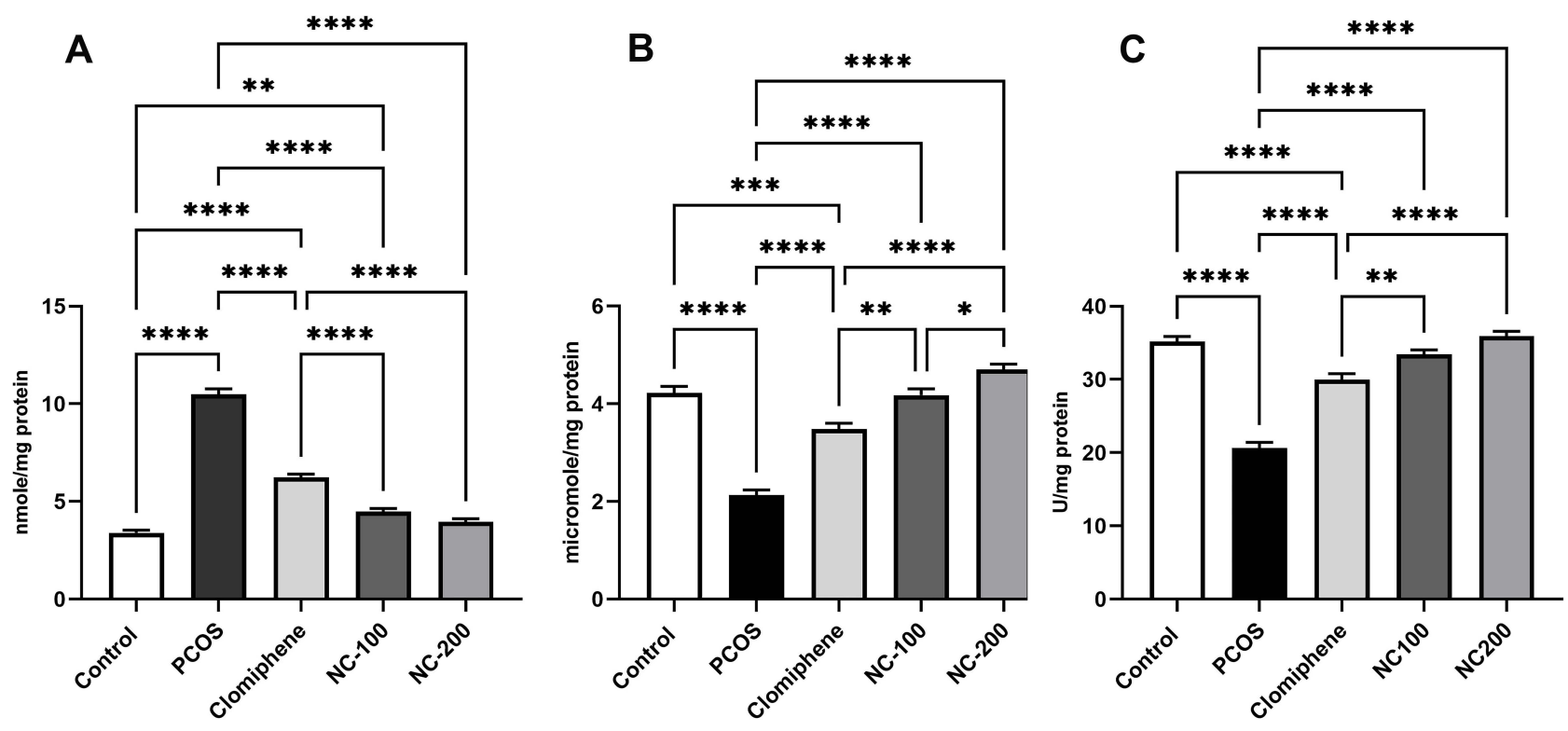

Figure 4 Oxidative stress status in different groups showing (A) MDA, (B) GSH, (C) CAT enzyme *Denotes $p$ value $<0.05$, **Denotes p value $<0.01$, *** Denotes $p$ value $<$ 0.001 , *****Denotes $p$ value $<0.0001$. 


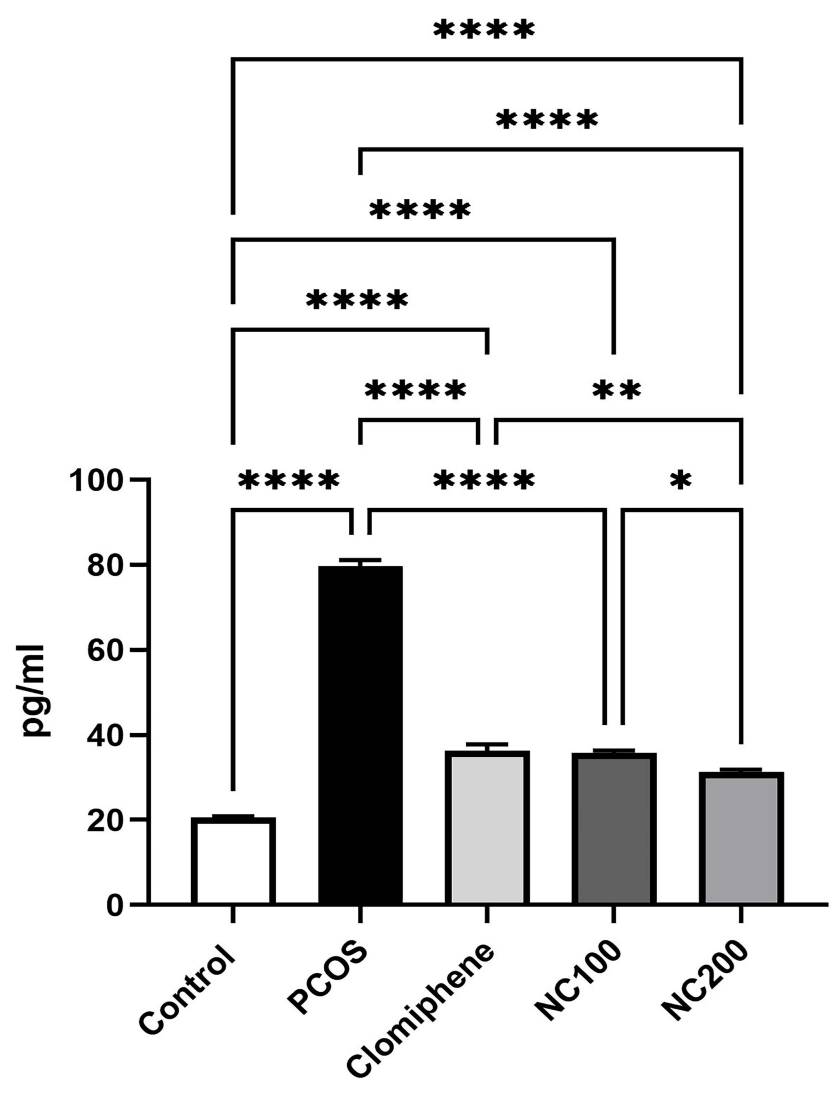

Figure 5 IL-6 level in different groups. *Denotes $\mathrm{p}$ value $<0.05$, **Denotes $\mathrm{p}$ value $<0.0 \mathrm{I}$, $* * * *$ Denotes $\mathrm{p}$ value $<0.000 \mathrm{I}$.

Clomiphene treatment as the standard group showed significant improvement in the granulosa lining and the detected oocytes. Meanwhile, nanocurcumin treated groups showed a dose-dependent improvement of the granulose cells and the development of oocytes was obviously noticed with the NC-200 group (Figure 8).

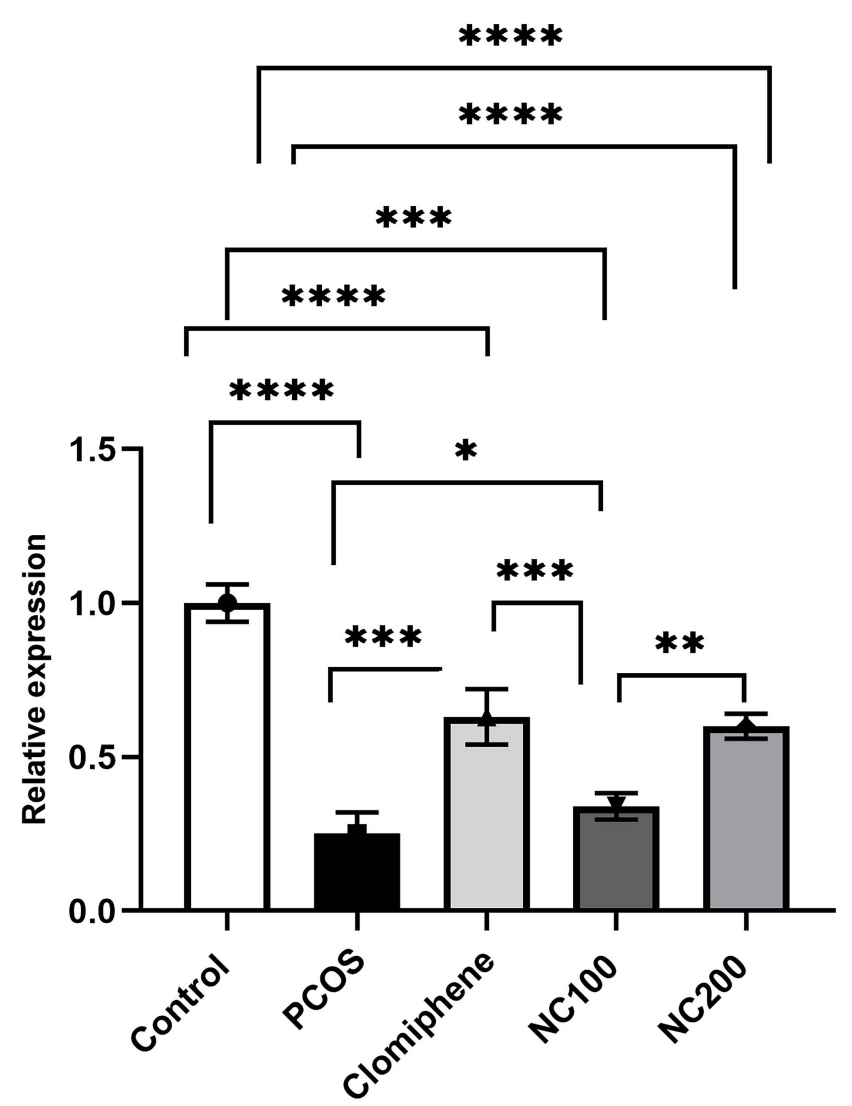

Figure 6 Relative quantification of miR-223-3p (Average of triplicates) using $\Delta \Delta \mathrm{Ct}$ formula. *Denotes $p$ value $<0.05$, **Denotes $p$ value $<0.01$, ***Denotes $p$ value $<$ 0.001 , $* * * *$ Denotes $p$ value $<0.0001$.

\section{Pancreatic Tissue Examination}

The PCOS group manifested dramatic pancreatic tissue changes revealed as numerous spreading of vacuolation and significant decrease of islet mass. Clomiphene and nanocurcumin treatment significantly restored pancreatic
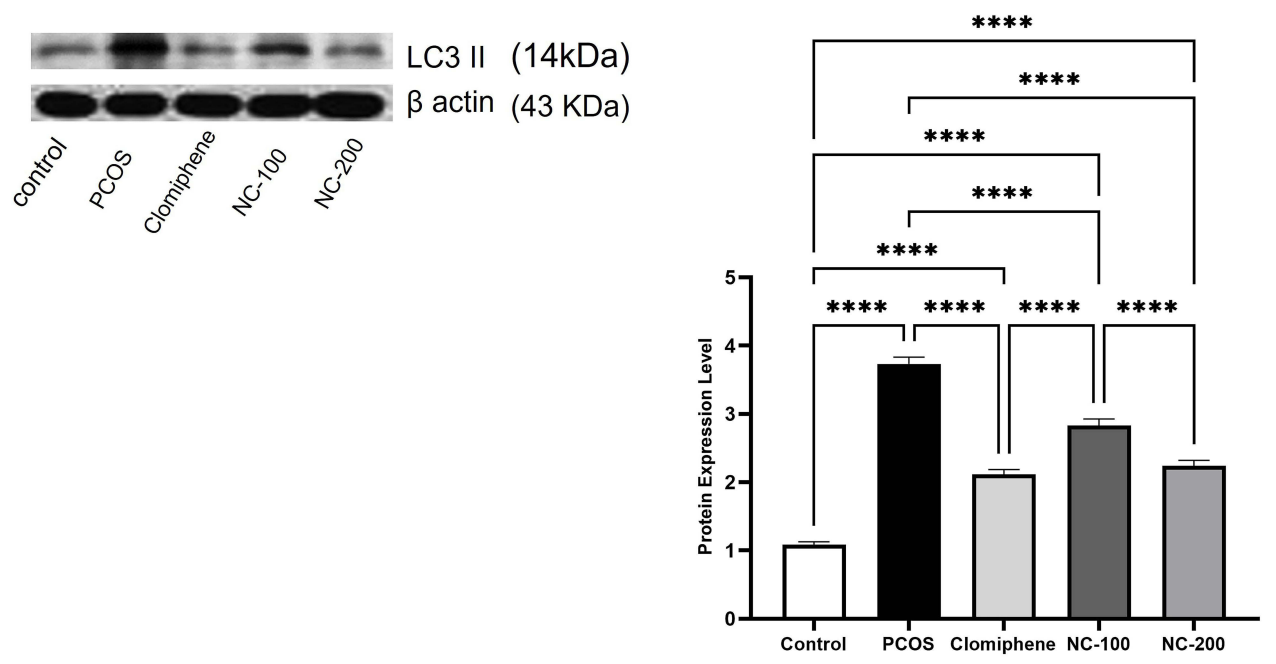

Figure 7 Illustration of LC3II protein expression Western blotting analysis (average of triplicates) in the different groups. $* * * *$ Denotes $\mathrm{P}$ value $<0.000 \mathrm{I}$. 


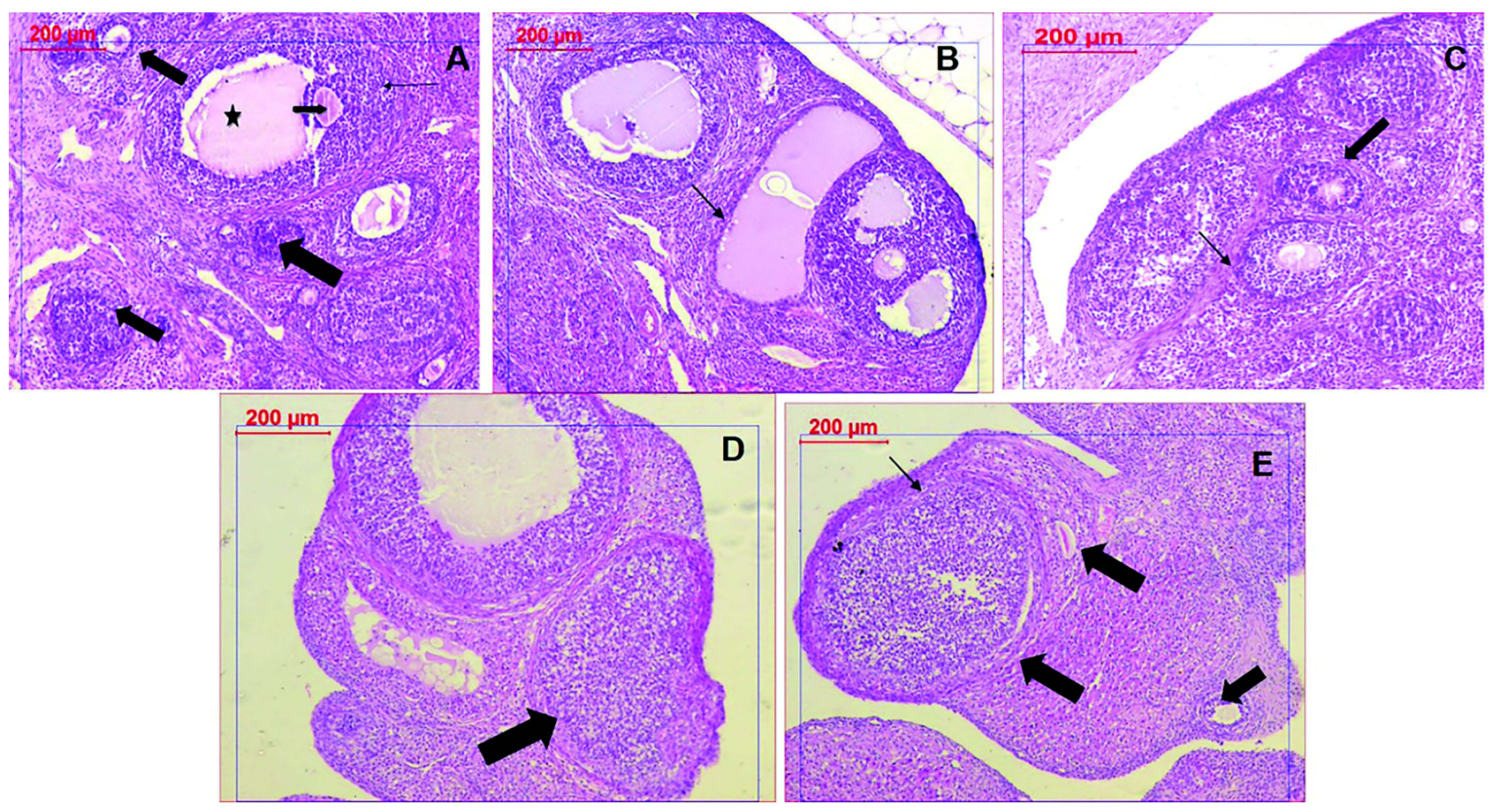

Figure 8 Histopathological examination of ovarian tissues in different groups. (A) Control group showing healthy follicles with oocytes (arrows) and antrum (star). (B) PCOS tissue showing numerous large cysts, and absence of oocytes. (C) Clomiphene treatment showing thicker granulosa cells and oocytes (D) NC-I00 treated group showing normal granulosa cells and follicle (E) NC-200 group showing granulosa cells, normal follicles, and oocytes.

tissue integrity in a dose-dependent manner, noticed as the absence of vacuoles and normal islet appearance (Figure 9).

\section{Immunohistochemistry}

Insulin staining was specifically localized in $\beta$-cells denoting islet mass. The PCOS group exhibited a drastic decrease in
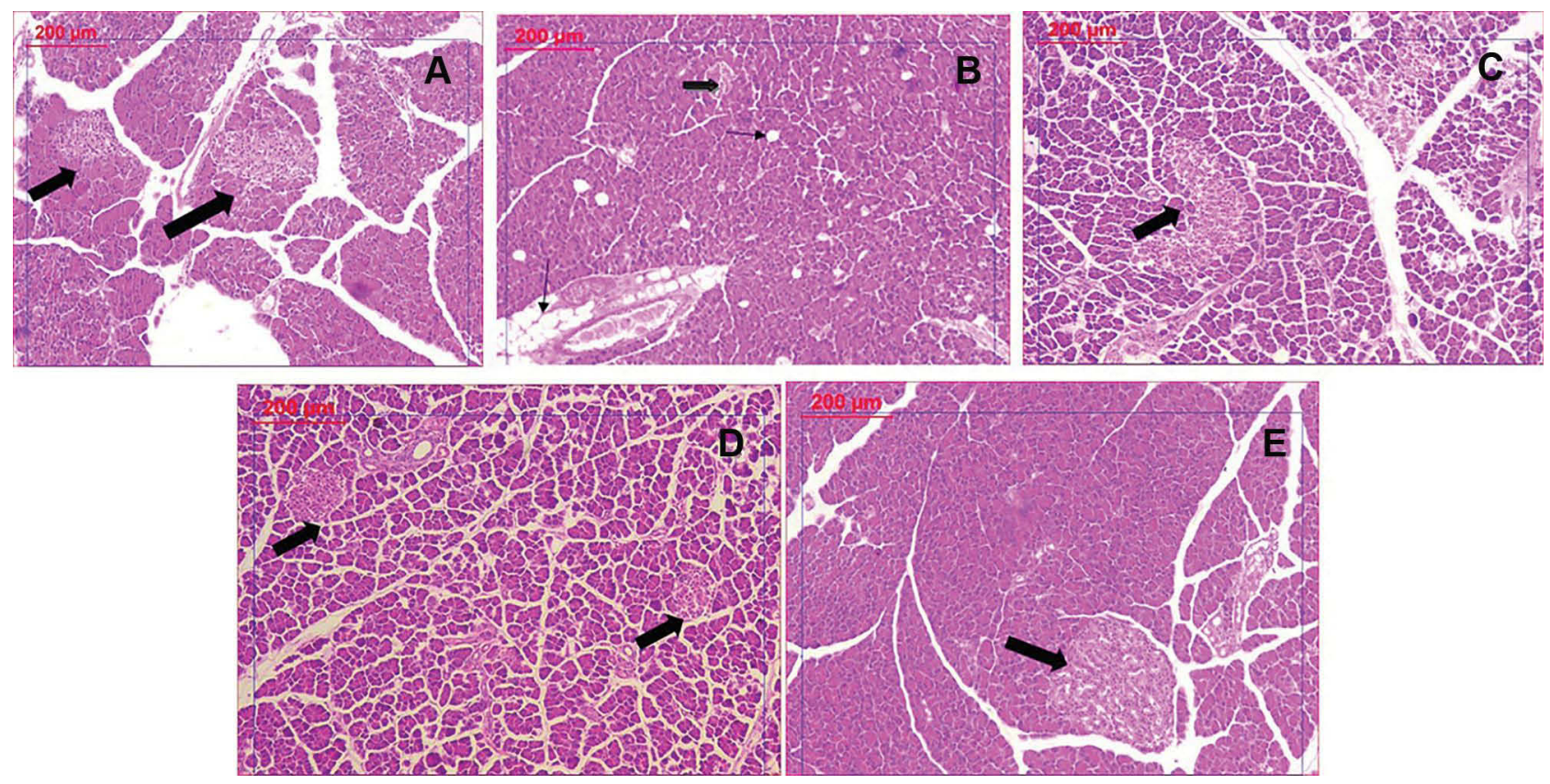

Figure 9 Histological examination of pancreatic tissues stained by H\&E: (A) Control group showing normal islets. (B) PCOS group revealing significant decrease in islet mass (thick arrow) and increased vacuolation (thin arrow). (C) Clomiphene treatment showing improved islets and less vacuoles. (D and E): Nanocurcumin treated groups $\mathrm{NC}-100$ and NC-200 respectively showing restored islet mass and absence of vacuoles. 
$\beta$-cell number, whereas treatment with nanocurcumin caused remarkable improvement in islets area and $\beta$-cell count, proportional to the used doses (Figure 10).

Meanwhile, the immunostaining of PCOS pancreatic tissues showed highly positive cytoplasmic and nuclear staining for NF- $\mathrm{BB}$ and p62 indicating inflammation flare, and increased autophagy activity. Clomiphene treatment and nanocurcumin $(200 \mathrm{mg} / \mathrm{kg})$ treated groups showed remarkable improvement noted by weak staining. Images analysis confirmed the dramatic effects of PCOS on inflammation and autophagy markers, and the significant improvement in the use of Nanocurcumin $(\mathrm{p}<0.05)$. Detailed data analysis of NF-kB, p62 expressions and photomicrographs are shown in Table 2 and Figure 11, respectively.

\section{Discussion}

The crucial roles of chronic inflammation and persistent oxidative stress are continuously confirmed in PCOSrelated pathologies. ${ }^{44}$ Furthermore, an increasing body of evidence shows that inflammation and oxidative stress interplay can modulate autophagy in multiple disorders. However, this approach is rarely explored in PCOS pancreatic pathology. Therefore, we explored the autophagy status in PCOS pancreas and analyze the regulatory roles of miR-223-3p and NF- $\kappa B$ as pivotal contributors to insulin and $\beta$ cell integrity. We also explored the probable modulating effect of nanocurcumin as a potent antioxidant/ anti-inflammatory nutraceutical on these disturbed factors.

PCOS pathology was successfully accomplished in our model using letrozole. This was manifested by the significant elevation of testosterone hormone, decrease of estradiol and progesterone hormones, and the detection of numerous ovarian cysts and anovulation as confirmed by histological examination. These manifestations comply with previous studies that used letrozole as an established PCOS inducer in animal models. ${ }^{24,27}$

Pancreatic examination revealed excessive activation of autophagy as revealed by the drastic elevations of LC3II and p62 proteins that are specifically significant for autophagy activity and autophagosome production. Under normal conditions, autophagy is critical for maintaining cellular homeostasis by retaining useful cellular content, preserving genomic integrity, and eradicating damaged misfolded proteins. However, excessive autophagy results in massive organoid degradation that promotes cell deterioration and death. ${ }^{45}$ This was further confirmed by the histological examination of PCOS pancreas in the current study that showed excessive deterioration $\beta$ cell mass and increased islet vacuolation.

To obtain a deeper understanding of inflammation and autophagy modulators, miR-223-3p was mainly chosen in the current study, as it is an established key

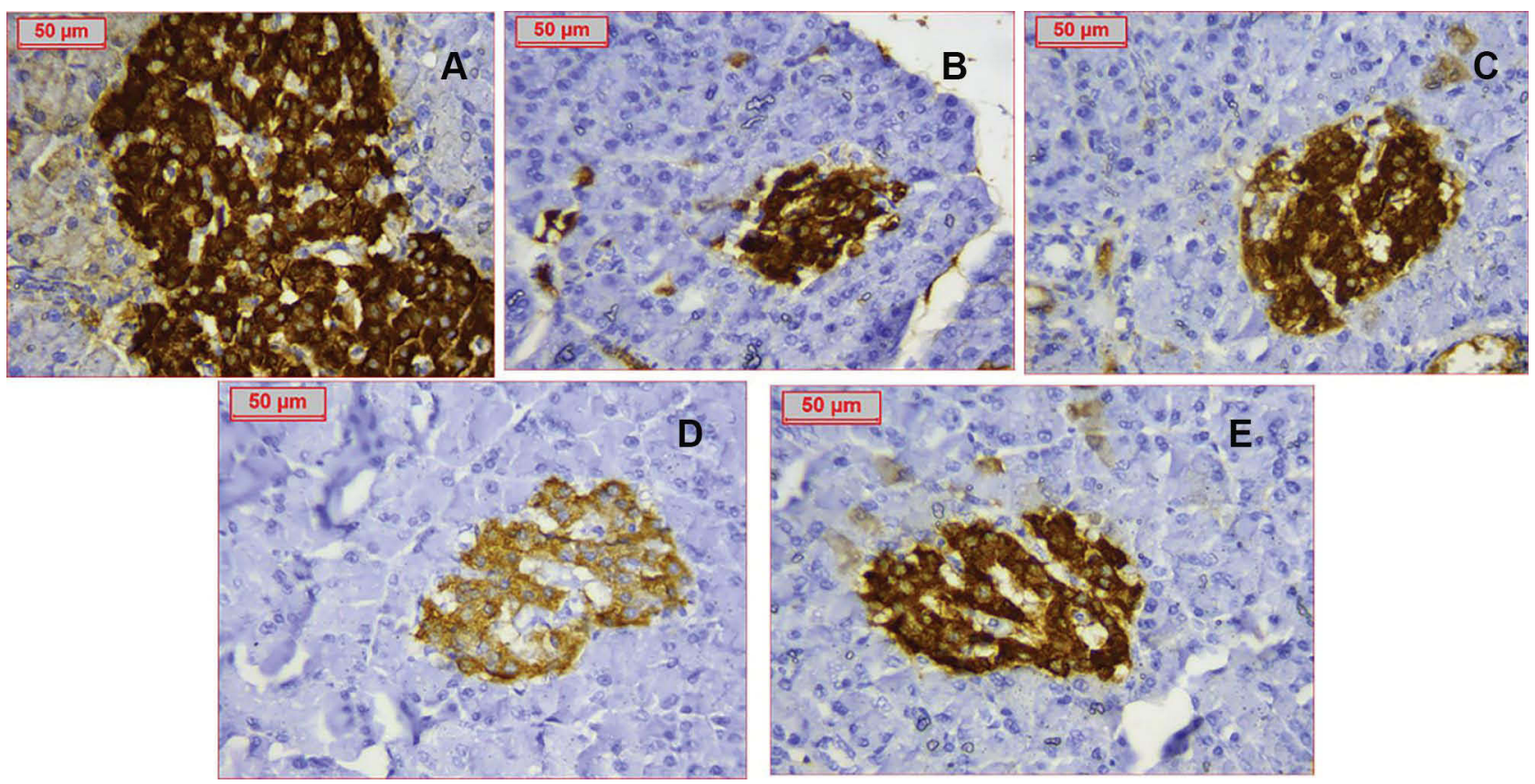

Figure 10 Immunostaining of insulin referring to B-cells of all groups (A) Control group with assessed B cells count I60 (B) PCOS group showing dramatic decrease of Bcells number to around 85 (C) Clomiphene treatment with B-cells number improved to 145 (D) Nanocurcumin - 100 treated group (E) Nanocurcumin-200 treated group showing increased B-cells mass. Assessed B-cells numbers were respectively 127 and 139 cells. 
Table 2 Data Analysis of NF-kB and P62 Expression

\begin{tabular}{|l|c|c|}
\hline Groups & NF-kB & p62 \\
\hline Control & $0.008 \pm 0.002$ & $0.092 \pm 0.05$ \\
\hline PCOS & $3.7 \pm 0.9^{\mathrm{a}, \mathrm{c}}$ & $7.19 \pm 2.6^{\mathrm{a}, \mathrm{c}}$ \\
\hline Clomiphene & $1.6 \pm 0.82^{\mathrm{b}}$ & $0.46 \pm 0.094^{\mathrm{b}}$ \\
\hline NC-100 & $2.3 \pm 0.53^{\mathrm{c}}$ & $4.23 \pm 1.9^{\mathrm{c}}$ \\
\hline NC-200 & $1.2 \pm 0.63^{\mathrm{b}}$ & $0.57 \pm 0.1^{\mathrm{b}}$ \\
\hline
\end{tabular}

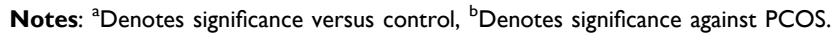
'Denotes significance versus clomiphene.

anti-inflammatory miRNA. Its protective effect was recently found to conserve $\beta$ cell functions in obesity and diabetes. Furthermore, miR-223-3p is reported as a specific pancreatic biomarker that predicts the progression of pre-diabetes. ${ }^{46,47}$ Additionally, recent reports recognized the detrimental role of miR-223-3p in autophagy process through suppressing NF- $\kappa$ B. ${ }^{48,49}$ However, to the best of our knowledge, no data on miR-223-3p level in PCOS pancreas is available. Real-time PCR quantification revealed significant downregulation of miR-223-3p in the PCOS group compared with the normal control. This finding coordinates with the persistent low inflammatory status known in PCOS. ${ }^{44}$ Furthermore, it agrees with recent studies that reported the downregulation of pancreatic miR-223-3p in an animal model of diabetes ${ }^{50}$ and associated miR-223-3p downregulation with deteriorated $\beta$ cell functions and mass by targeting FOXO gene. ${ }^{51}$

Therefore, bioinformatics analysis was conducted to clarify the relevant target genes of miR-223-3p. Target gene prediction analysis revealed that $\mathrm{miR}-223-3 \mathrm{p}$ prominently targets inflammatory factors; IL6ST, NF-IB and NF-IA that activate
NF- $\kappa$ B. Additionally, miR-223-3p regulates genes that contribute to autophagy and insulin signaling including (FOXO1, FOXO3, Ataxin, ATG7, IL-6) (See also Supplementary File;

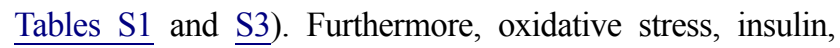
inflammatory and autophagic signaling were the most prominent processes regulated by miR-223-3p genes. Whereas PI3k/AKT signaling and PCOS were the topmost significant pathway, and disease relevant to these target genes, respectively. This in silico analysis coordinated with our findings, where the downregulation of miR-223-3p contributed to excessive autophagy activity and consequent $\beta$ cell death.

Moreover, our findings are in line with recent studies that showed the protective effects of miR-223-3p activation on suppressing autophagy by activating the AKT/ mTOR pathway. ${ }^{19,52}$ Interestingly, we recently reported decreased PI3k/AKT/mTOR levels in PCOS. ${ }^{12}$ Taken together, these results might resolve miR-223-3p as an essential jigsaw upregulator to the disturbed pathway and associated pathologies in PCOS pancreas.

To further verify our in silico analysis results, we investigated the levels of the inflammatory markers; IL-6 and NF$\mathrm{kB}$, with oxidative stress markers and metabolic profile.

Indeed, PCOS rats exhibited drastic elevation of pancreatic IL-6 and NF-kB levels which agreed with the bioinformatics prediction. NF- $\mathrm{B}$ expression and release are vital for $\beta$ cell functionality, insulin secretion and normoglycemia maintenance under normal physiological conditions. $^{53}$ However, the overexpression of NF- $\kappa \mathrm{B}$ is strongly linked to impaired insulin secretion, poor insulin binding to receptors, and excessive $\beta$-cell death. ${ }^{54,55}$ Furthermore, prolonged exposure to chronic inflammatory cytokines provokes and maintains the release of reactive oxygen species (ROS) that induces excessive production

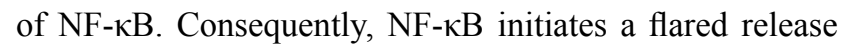
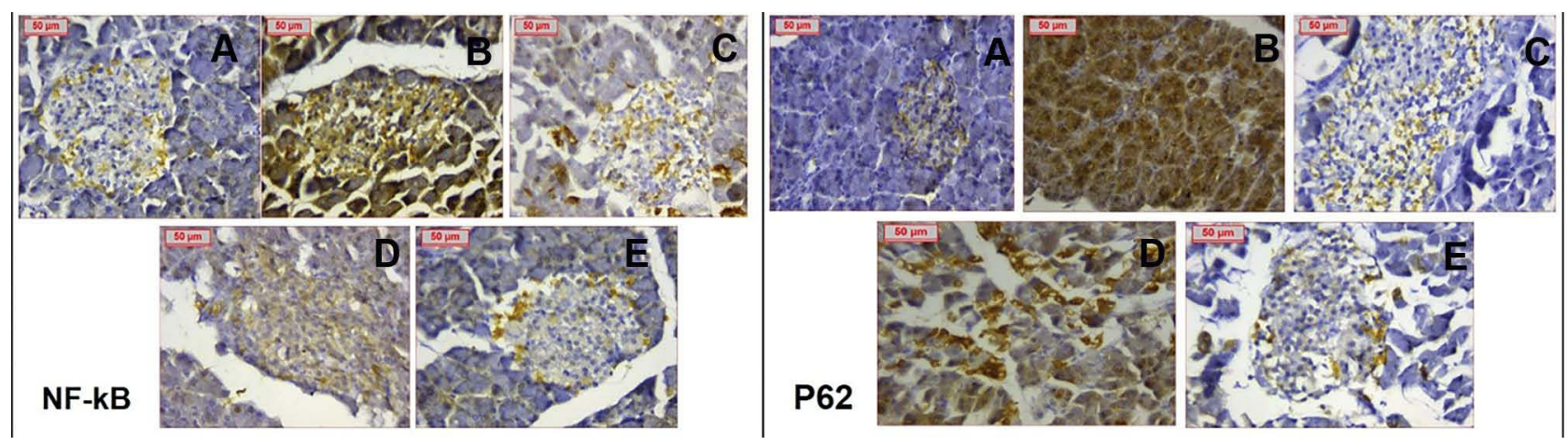

Figure II Immunohistochemical staining of NF- $\mathrm{KB}$ and p62 respectively showing (A) negatively stained normal control (B) PCOS group showing extensively positive staining (C) Clomiphene group showing weak staining (D) NC-100 group showing weaker staining compared to PCOS \& (E) NC-200 group showing weak staining. (Magnification X400). 
of inflammatory molecules (TNF- $\alpha$, IL-6 and IL-1 $\beta$ ) that disrupt insulin secretion, insulin binding to receptors and glucose uptake by tissues, eventually resulting in insulin resistance. ${ }^{56,57}$

In addition, PCOS rats exhibited decreased $\beta$ cell mass, significant hyperglycemia and hyperinsulinemia that culminated in insulin resistance. Furthermore, PCOS rats manifested impaired pancreatic antioxidant defense mechanisms as shown by the significant decrease in $\mathrm{GSH}$ and catalase enzyme, together with MDA elevation, denoting high oxidative stress. In line with our findings, numerous studies have previously confirmed the disturbed metabolic profile and eruption of insulin in PCOS rat model, as well as clinically. ${ }^{12,21,27,28}$

Collectively, these results are in harmony where decreased miR-223-3p levels contributed to the hyperactivation of inflammatory and autophagy actions of NF- $\kappa B$ and IL-6 which were highly expressed in PCOS pancreas and are direct targets of miR-223-3p. Most importantly, our results go in line with emerging studies that identified the protective and metabolic regulatory actions of miR223-3p by targeting NF- $\kappa$ B, IL6ST and autophagy-related proteins. $^{18,50,51,58,59}$

The above observations support the importance of modulating the chronic inflammatory status as a promising means for attenuating the disruptions in PCOS pancreas. Polyphenols are naturally derived compounds that have proved remarkable potency against multiple metabolic and inflammatory disorders via their capability to modulate inflammation molecules and ROS. $^{60,61}$

Among polyphenols, curcumin proved promising results in adjusting metabolic and cellular disturbances in PCOS studies. ${ }^{12,21}$ In the present study, curcumin was formulated in a biocompatible nanoform to enhance curcumin solubility and facilitate its oral administration. ${ }^{45}$ TEM microscopy and FT-IR spectroscopy proved the successful formulation of curcumin in the nano range while preserving the chemical active entities of curcumin. ${ }^{62}$ Whereas the zeta potential analysis revealed the acceptable charge that denotes the stability of the dispersed formula, in agreement with previous studies. ${ }^{63,64}$

Clomiphene, as the standard drug of choice for PCOS, reinstated the sex hormone levels. Whereas nanocurcumin significantly improved testosterone disrupted levels, and increased estrogen and progesterone hormones. These effects are mainly attributed to the potent phytoestrogenic property of curcumin. ${ }^{65}$ Furthermore, these findings were histologically confirmed, as the nanocurcumin groups showed remarkable improvement of ovulation and decreased abnormal cysts.

Interestingly, nanocurcumin managed to upregulate miR-223-3p expression. It attenuated the autophagy flare in pancreatic tissues as confirmed by decreased levels of LC3II, p62 proteins and a remarkable increase in $\beta$ cell mass. The powerful antioxidant potential of nanocurcumin helps restore cellular homeostasis and combats the drastic impact of persistent high ROS levels on the cross talk between miRNAs and cell proliferation pathways. ${ }^{66}$ Moreover, the protective potential of curcumin as a powerful autophagy modulator is gradually emerging, as curcumin was found to reinstate balanced autophagy in various diseases by manipulating the AKT/mTOR pathway and suppressing autophagy proteins including ATG7 and p62. ${ }^{67,68}$

In addition, nanocurcumin significantly attenuated the oxidative stress in pancreatic tissues by restoring GSH and CAT enzyme levels, which led to decreased MDA accumulation. Simultaneously, nanocurcumin treatment significantly reduced IL-6 levels and diminished NF-kB expression, eventually attenuating the inflammation flare in the pancreas. The distinguished dual action of nanocurcumin as a potent antioxidant and anti-inflammatory agent has been previously stated $^{12,21,44,68}$ On the molecular level, restoring oxidative stress and inflammation conditions close to normal conditions culminated in adjusted serum insulin and glucose levels and remarkable recovery of $\beta$ cell mass, eventually leading to attenuation of the insulin resistance. Interestingly, emerging clinical trials are showing promising results for curcumin administration in PCOS and fatty liver. ${ }^{21,69,70}$ Where curcumin effectively reduces the oxidative stress and inflammatory molecules that contribute to the loss of $\beta$ cell mass and disturbed glucose metabolism. Moreover, the estrogenic activity of curcumin can attenuate the disturbed testosterone secretion by PCOS ovaries, decreasing the resulting oxidative stress conditions.

\section{Conclusion}

Altogether, the findings of this study identified for the first time the vital contribution of pancreatic NF- $\kappa \mathrm{B}$ and mir223-3p levels in PCOS pancreatic impairments. The study also highlights the promising ability of nanocurcumin as an anti-inflammatory nutraceutical, to modulate the inflammatory-autophagy axis in the metabolic complications of PCOS. Further studies are highly encouraged to 
uncover the full potential of modulating the inflammationautophagy axis in PCOS pathologies.

\section{Data Sharing Statement}

Data are available upon reasonable request sent to corresponding author.

\section{Disclosure}

The authors report no conflicts of interest in this work.

\section{References}

1. Witchel SF, Oberfield SE, Peña AS. Polycystic ovary syndrome: pathophysiology, presentation, and treatment with emphasis on adolescent girls. J Endocr Soc. 2019;3(8):1545-1573.

2. Nasser HA, Ezz NZA, Abdel-Mageed HM, Radwan RA. Body mass index and c-reactive protein are potential predictors of asthma development in Egyptian polycystic ovary syndrome patients. $J$ Med Biochem. 2019;38(4):427-436. doi:10.2478/jomb-2019-0012

3. Osibogun O, Ogunmoroti O, Michos ED. Polycystic ovary syndrome and cardiometabolic risk: opportunities for cardiovascular disease prevention. Trends Cardiovasc Med. 2020;30(7):399-404. doi:10.1016/j.tcm.2019.08.010

4. Radwan RA, Abuelezz NZ, Abdelraouf SM, Bakeer EM, Rahman AAAE. Decreased serum level of gamma-amino butyric acid in Egyptian infertile females with polycystic ovary syndrome is correlated with dyslipidemia, total testosterone and $25(\mathrm{OH})$ Vitamin D levels. $J$ Med Biochem. 2019;38(4):512-518. doi:10.2478/jomb-2018-0051

5. Rojas J, Chávez M, Olivar L, et al. Polycystic ovary syndrome, insulin resistance, and obesity: navigating the pathophysiologic labyrinth. Int J Reprod Med. 2014; 2014:1-17. doi: 10.1155/2014/ 719050

6. Xita N, Papassotiriou I, Georgiou I, Vounatsou M, Margeli A, Tsatsoulis A. The adiponectin-to-leptin ratio in women with polycystic ovary syndrome: relation to insulin resistance and proinflammatory markers. Metab Clin Exp. 2007;56(6):766-771. doi:10.1016/j. metabol.2007.01.008

7. Furman D, Campisi J, Verdin E, et al. Chronic inflammation in the etiology of disease across the life span. Nat Med. 2019;25 (12): 1822-1832. doi:10.1038/s41591-019-0675-0

8. Chen L, Deng H, Cui H, et al. Inflammatory responses and inflammation-associated diseases in organs. Oncotarget. 2017;9 (6):7204-7218. doi:10.18632/oncotarget.23208

9. Verzella D, Pescatore A, Capece D, et al. Life, death, and autophagy in cancer: NF-kB turns up everywhere. Cell Death Dis. 2020;11 (3):1-14. doi:10.1038/s41419-020-2399-y

10. Mancini A, Bruno C, Vergani E, d'Abate C, Giacchi E, Silvestrini A. Oxidative stress and low-grade inflammation in polycystic ovary syndrome: controversies and new insights. Int J Mol Sci. 2021;22 (4):1667. doi:10.3390/ijms22041667

11. Khandia R, Dadar M, Munjal A, et al. A comprehensive review of autophagy and its various roles in infectious, non-infectious, and lifestyle diseases: current knowledge and prospects for disease prevention, novel drug design, and therapy. Cells. 2019;8(7):674.

12. Abuelezz NZ, Shabana ME, Abdel-Mageed HM, Rashed L, Morcos GNB. Nanocurcumin alleviates insulin resistance and pancreatic deficits in polycystic ovary syndrome rats: insights on PI3K/ AkT/mTOR and TNF- $\alpha$ modulations. Life Sci. 2020;256:118003. doi:10.1016/j.lfs.2020.118003

13. Huang X, Liu G, Guo J, The SZ. PI3K/AKT pathway in obesity and type 2 diabetes. Int J Biol Sci. 2018;14(11):1483-1496. doi:10.7150/ ijbs. 27173
14. Qin H, Xu H-Z, Gong Y-Q. Mechanism of NF-אB signaling pathway and autophagy in the regulation of osteoblast differentiation. Mol Membr Biol. 2016;33(6-8):138-144. doi:10.1080/09687688.2017. 1400601

15. Gentle IE. Supramolecular complexes in cell death and inflammation and their regulation by autophagy. Front Cell Dev Biol. 2019;7:73. doi:10.3389/fcell.2019.00073.

16. Zhang N, Valentine JM, Zhou Y, et al. Sustained NFkB inhibition improves insulin sensitivity but is detrimental to muscle health. Aging Cell. 2017;16(4):847-858. doi:10.1111/acel.12613

17. Zhou W, Pal AS, Hsu AY-H, et al. MicroRNA-223 suppresses the canonical NF- $\kappa B$ pathway in basal keratinocytes to dampen neutrophilic inflammation. Cell Rep. 2018;22(7):1810-1823. doi:10.1016/j. celrep.2018.01.058

18. Zhou Y, Chen E, Tang Y, et al. miR-223 overexpression inhibits doxorubicin-induced autophagy by targeting FOXO3a and reverses chemoresistance in hepatocellular carcinoma cells. Cell Death Dis. 2019;10(11):1-13. doi:10.1038/s41419-019-2053-8

19. Zhu H, Leung SW. Identification of microRNA biomarkers in type 2 diabetes: a meta-analysis of controlled profiling studies. Diabetologia. 2015;58(5):900-911. doi:10.1007/s00125-015$3510-2$

20. Hahn D, Shin SH, Bae JS. Natural antioxidant and anti-inflammatory compounds in foodstuff or medicinal herbs inducing heme oxygenase-1 expression. Antioxidants (Basel). 2020;9(12):1191.

21. Heshmati J, Moini A, Sepidarkish M, et al. Effects of curcumin supplementation on blood glucose, insulin resistance and androgens in patients with polycystic ovary syndrome: a randomized double-blind placebo-controlled clinical trial. Phytomedicine. 2021;80(80):153395. doi:10.1016/j.phymed.2020.153395

22. Shakeri A, Cicero AFG, Panahi Y, Mohajeri M, Sahebkar A. Curcumin: a naturally occurring autophagy modulator. $J$ Cell Physiol. 2019;234(5):5643-5654. doi:10.1002/jcp.27404

23. Karthikeyan A, Senthil N, Min T. Nanocurcumin: a promising candidate for therapeutic applications. Front Pharmacol.. 2020;11:487.

24. Kafali H, Iriadam M, Ozardali I, Demir N. Letrozole-induced polycystic ovaries in the rat: a new model for cystic ovarian disease. Arch Med Res. 2004;35(2):103-108. doi:10.1016/j.arcmed. 2003.10.005

25. Li D, Li C, Xu Y, et al. Differential expression of microRNAs in the ovaries from letrozole-induced rat model of polycystic ovary syndrome. DNA Cell Biol. 2016;35(4):177-183. doi:10.1089/ dna.2015.3145

26. Faul F, Erdfelder E, Lang A-G, Buchner A. G*Power 3: a flexible statistical power analysis program for the social, behavioral, and biomedical sciences. Behav Res Methods. 2007;39(2):175-191. doi:10.3758/BF03193146

27. Reddy PS, Begum N, Mutha S, Bakshi V. Beneficial effect of curcu$\mathrm{min}$ in letrozole induced polycystic ovary syndrome. Asian Pacific $J$ Reprod. 2016;5(2):116. doi:10.1016/j.apjr.2016.01.006

28. Saiyed A, Jahan N, Makbul SAA, Ansari M, Bano H, Habib SH. Effect of combination of withania somnifera dunal and tribulus terrestris linn on letrozole induced polycystic ovarian syndrome in rats; 2016. Available from: https://core.ac.uk/display/82754899. Accessed August 13, 2021.

29. Agarwal V, Bell GW, Nam JW, Bartel DP. Predicting effective microRNA target sites in mammalian mRNAs. eLife. 2015;4: e05005. doi:10.7554/eLife. 05005

30. Chen Y, Wang X. miRDB: an online database for prediction of functional microRNA targets. Nucleic Acids Res. 2020;48(D1): D127-31. doi:10.1093/nar/gkz757

31. Paraskevopoulou MD, Georgakilas G, Kostoulas N, et al. DIANAmicroT web server v5.0: service integration into miRNA functional analysis workflows. Nucleic Acids Res. 2013;41(Web Server issue): W169-73. doi:10.1093/nar/gkt393 
32. Mi H, Muruganujan A, Huang X, et al. Protocol Update for largescale genome and gene function analysis with the PANTHER classification system (v.14.0). Nat Protoc. 2019;14(3):703-721. doi:10.1038/s41596-019-0128-8. Protocol Update for large-scale genome and gene function analysis with the PANTHER classification system (v.14.0) | nature Protocols [Internet]; 2021. Available from: https://www.nature.com/articles/s41596-019-0128-8? error= cookies_not_supported $\& \operatorname{code}=5 \mathrm{bf} 15 \mathrm{f} 1 \mathrm{c}-7 \mathrm{bf} 8-49 \mathrm{a} 2-8335$ 9fc8bc10eb3e. Accessed August 13, 2021.

33. Chen J, Bardes EE, Aronow BJ, Jegga AG. ToppGene Suite for gene list enrichment analysis and candidate gene prioritization. Nucleic Acids Res. 2009;37(Web Server issue):W305-11. doi:10.1093/nar/ gkp427

34. Trinder P. Determination of blood glucose using an oxidase-peroxidase system with a non-carcinogenic chromogen. J Clin Pathol. 1969;22(2):158-161. doi:10.1136/jcp.22.2.158

35. Diamanti-Kandarakis E, Dunaif A. Insulin resistance and the polycystic ovary syndrome revisited: an update on mechanisms and implications. Endocr Rev. 2012;33(6):981-1030. doi:10.1210/ er.2011-1034

36. Sato S, Imachi H, Lyu J, et al. Effect of TNF- $\alpha$ on the expression of ABCA1 in pancreatic $\beta$-cells. $J$ Mol Endocrinol. 2018;61 (4):185-193. doi:10.1530/JME-18-0167

37. Aebi H. Catalase in vitro. Methods Enzymol. 1984;105:121-126.

38. Beutler E, Duron O, Kelly BM. Improved method for the determination of blood glutathione. $J$ Lab Clin Med. 1963;61:88 2-888.

39. Kumar S, Reddy PH. MicroRNA-455-3p as a potential biomarker for alzheimer's disease: an update. Front Aging Neurosci. 2018;10. Available from: https://www.ncbi.nlm.nih.gov/pmc/articles/ PMC5829054/.

40. Feng F-B, Qiu H-Y. Effects of Artesunate on chondrocyte proliferation, apoptosis and autophagy through the $\mathrm{PI} 3 \mathrm{~K} / \mathrm{AKT} / \mathrm{mTOR}$ signaling pathway in rat models with rheumatoid arthritis. Biomed Pharmacother. 2018;102:1209-1220. doi:10.1016/j. biopha.2018.03.142

41. Cemek M, Kaga S, Simsek N. et al. Antihyperglycemic and antioxidative potential of Matricaria chamomilla $L$. in streptozotocin-induced diabetic rats - PubMed [Internet]. Available from: https://pubmed.ncbi.nlm.nih.gov/18404309/. Accessed August 13, 2021.

42. Bratthauer GL. The avidin-biotin complex (ABC) method and other avidin-biotin binding methods. Methods Mol Biol. 2010;588:257-270.

43. Riffo-Campos ÁL, Riquelme I, Brebi-Mieville P. Tools for sequence-based miRNA target prediction: what to choose? Int J Mol Sci. 2016;17:12. doi:10.3390/ijms17121987

44. Heshmati J, Golab F, Morvaridzadeh M, et al. The effects of curcumin supplementation on oxidative stress, Sirtuin-1 and peroxisome proliferator activated receptor $\gamma$ coactivator $1 \alpha$ gene expression in polycystic ovarian syndrome (PCOS) patients: a randomized placebocontrolled clinical trial. Diabetes Metab Syndr Clin Res Rev. 2020;14 (2):77-82. doi:10.1016/j.dsx.2020.01.002

45. Ichimiya $T$, Yamakawa $T$, Hirano $T$, et al. Autophagy and autophagy-related diseases: a review. Int J Mol Sci. 2020;21 (23):8974.

46. Deng B, Hu Y, Sheng X, Zeng H, Huo Y. miR-223-3p reduces high glucose and high fat-induced endothelial cell injury in diabetic mice by regulating NLRP3 expression. Exp Ther Med. 2020;20 (2):1514-1520. doi:10.3892/etm.2020.8864

47. Seyhan AA. microRNAs with different functions and roles in disease development and as potential biomarkers of diabetes: progress and challenges. Mol BioSyst. 2015;11(5):1217-1234. doi:10.1039/ C5MB00064E
48. Zhang M-W, Shen Y-J, Shi J, Yu J-G. MiR-223-3p in cardiovascular diseases: a biomarker and potential therapeutic target. Front Cardiovasc Med. 2021;7. Available from:. https://www.frontiersin. org/articles/10.3389/fcvm.2020.610561/full.

49. Wang H, Chen J, Zhang S, et al. MiR-223 regulates autophagy associated with cisplatin resistance by targeting FBXW7 in human non-small cell lung cancer. Cancer Cell Int. 2020;20(1):258. doi:10.1186/s12935-020-01284-x

50. Nesca V, Guay C, Jacovetti C, et al. Identification of particular groups of microRNAs that positively or negatively impact on beta cell function in obese models of type 2 diabetes. Diabetologia. 2013;56 (10):2203-2212.

51. Li Y, Deng S, Peng J, et al. MicroRNA-223 is essential for maintaining functional $\beta$-cell mass during diabetes through inhibiting both FOXO1 and SOX6 pathways. $J$ Biol Chem. 2019;294:10438-10448.

52. Liu X, Deng Y, Xu Y, Jin W, Li H. MicroRNA-223 protects neonatal rat cardiomyocytes and $\mathrm{H} 9 \mathrm{c} 2$ cells from hypoxia-induced apoptosis and excessive autophagy via the Akt/mTOR pathway by targeting PARP-1. J Mol Cell Cardiol. 2018;118:133-146. doi:10.1016/j. yjmcc.2018.03.018

53. Norlin $\mathrm{S}$, Ahlgren $\mathrm{U}$, Edlund $\mathrm{H}$. Nuclear factor- $\mathrm{kB}$ activity in $\beta$-cells is required for glucose-stimulated insulin secretion. Diabetes. 2005;54(1):125-132. doi:10.2337/diabetes.54.1.125

54. Malin SK, Kirwan JP, Sia CL, González F. Pancreatic $\beta$-cell dysfunction in polycystic ovary syndrome: role of hyperglycemia-induced nuclear factor- $\mathrm{\kappa B}$ activation and systemic inflammation. APSselect. 2015;2(6):E770-E777.

55. Condorelli RA, Calogero AE, Mauro MD, Vignera SL. PCOS and diabetes mellitus: from insulin resistance to altered beta pancreatic function, a link in evolution. Gynecol Endocrinol. 2017;33 (9):665-667. doi:10.1080/09513590.2017.1342240

56. Rojas J, Bermudez V, Palmar J, et al. Pancreatic beta cell death: novel potential mechanisms in diabetes therapy. J Diabetes Res. 2018; e9601801. Available from https://www.hindawi.com/journals/jdr/ 2018/9601801/.

57. Chen L, Chen R, Wang H, Liang F. Mechanisms linking inflammation to insulin resistance. Int $J$ Endocrinol [Internet]. 2015;2015:1-9. doi:10.1155/2015/508409

58. Wang X, Ding Y, Chen Y, et al. MiR-223-3p alleviates vascular endothelial injury by targeting IL6ST in kawasaki disease. Front Pediatr. 2019;7:288.

59. Li Y, Zhou D, Ren Y, et al. Mir223 restrains autophagy and promotes CNS inflammation by targeting ATG16L1. Autophagy. 2019;15 (3):478-492. doi:10.1080/15548627.2018.1522467

60. Morvaridzadeh M, Fazelian S, Agah S, et al. Effect of ginger (Zingiber officinale) on inflammatory markers: a systematic review and meta-analysis of randomized controlled trials. Cytokine. 2020;1 (135):155224. doi:10.1016/j.cyto.2020.155224

61. Akbari-Fakhrabadi M, Heshmati J, Sepidarkish M, Shidfar F. Effect of sumac (Rhus Coriaria) on blood lipids: a systematic review and meta-analysis. Complement Ther Med. 2018;40:8-12. doi:10.1016/j. ctim.2018.07.001

62. Gouda W, Hafiz NA, Mageed L, et al. Effects of nano-curcumin on gene expression of insulin and insulin receptor. Bull Natl Res Cent. 2019;43(1):128. doi:10.1186/s42269-019-0164-0

63. Annaraj J, Dhivya R, Vigneshwar M, Dharaniyambigai K, Kumaresan G, Rajasekaran M. Studies on the enhanced biological applications of PVA loaded nanocurcumin. J Nanosci Nanotechnol. 2014;2(1):490-495.

64. Sivasami P, Hemalatha T. Augmentation of therapeutic potential of curcumin using nanotechnology: current perspectives. Artif Cells, Nanomed Biotechnol. 2018;46(sup1):1004-1015. doi:10.1080/ 21691401.2018.1442345 
65. Bachmeier BE, Mirisola V, Romeo F, et al. Reference profile correlation reveals estrogen-like transcriptional activity of curcumin. $C P B$. 2010;26(3):471-482.

66. Akbari A, Majd HM, Rahnama R, et al. Cross-talk between oxidative stress signaling and microRNA regulatory systems in carcinogenesis: focused on gastrointestinal cancers. Biomed Pharmacother. 2020;1 (131):110729. doi:10.1016/j.biopha.2020.110729

67. Pourbagher-Shahri AM, Farkhondeh T, Ashrafizadeh M, Talebi M, Samargahndian S. Curcumin and cardiovascular diseases: focus on cellular targets and cascades. Biomed Pharmacother. 2021;1 (136):111214. doi:10.1016/j.biopha.2020.111214

68. Perrone L, Squillaro T, Napolitano F, Terracciano C, Sampaolo S, Melone MAB. The autophagy signaling pathway: a potential multifunctional therapeutic target of curcumin in neurological and neuromuscular diseases. Nutrients. 2019;11(8):1881.
69. Chien Y-J, Chang C-Y, Wu M-Y, Chen C-H, Horng Y-S, $\mathrm{Wu} \mathrm{H}-\mathrm{C}$. Effects of curcumin on glycemic control and lipid profile in polycystic ovary syndrome: systematic review with meta-analysis and trial sequential analysis. Nutrients. 2021;13 (2):684.

70. Jazayeri-Tehrani SA, Rezayat SM, Mansouri S, et al. Nano-curcumin improves glucose indices, lipids, inflammation, and Nesfatin in overweight and obese patients with non-alcoholic fatty liver disease (NAFLD): a double-blind randomized placebo-controlled clinical trial. Nutr Metab (Lond). 2019;16:1-3.

\section{Publish your work in this journal}

The Journal of Experimental Pharmacology is an international, peerreviewed, open access journal publishing original research, reports, reviews and commentaries on all areas of laboratory and experimental pharmacology. The manuscript management system is completely online and includes a very quick and fair peer-review system. Visit http://www.dovepress.com/testimonials.php to read real quotes from published authors. 